\title{
UNBIASED STEREOLOGICAL ESTIMATION OF DIFFERENT CELL TYPES IN RAT CEREBRAL CORTEX
}

\author{
MAZIAR DAVANLOU ${ }^{1}$ AND DONALD F SMITH ${ }^{2}$ \\ ${ }^{1}$ Stereological Research Laboratory, University Institute of Pathology and $2^{\text {nd }}$ University Clinic of Internal \\ Medicine, Institute of Experimental Clinical Research, Aarhus University; ${ }^{2}$ Institute for Basic Research in \\ Psychiatry, Department of Biological Psychiatry, Psychopharmacology Research Group, Psychiatric Hospital, \\ Aarhus, Denmark \\ e-mail: maziar-d@mail.tele.dk \\ (Accepted January 28, 2004)
}

\begin{abstract}
The total numbers of neurons, glial cells, and endothelial cells in rat cerebral cortex were estimated using unbiased stereological counting techniques and systematic sampling. The reference volume chosen was the entire neocortex, most of the allocortex and parts of claustrum using the rhinal fissure as the macroscopical anatomical landmark. These regions are referred to collectively as syncortex. A method has been devised for reducing problems associated with the uncertainties that arise when distinguishing between various types of cells. At the light microscopic level, using the detailed criteria described in this article, the total numbers of neurons, glial cells, and endothelial cells, respectively, were estimated for the entire syncortex as the product of the estimate of the volume of the syncortex, made with point counting techniques, and the estimates of the numerical density for each group of cells, made with optical disectors. In a sample of three brains, the mean total number of cells (neurons, glial and endothelial) in the syncortex of the rat brain is $128 \times 10^{6}$. This number is made up of $47 \%$ neurons, $24 \%$ glial cells, $17 \%$ endothelial cells, and $11 \%$ uncertain cell types (probably mostly glial cells).
\end{abstract}

Key words: Cavalieri's estimator, cerebral cortex, endothelial cells, glia, morphological classification, neurons, optical disector, stereology, rat brain.

\section{INTRODUCTION}

During the past two decades a number of new stereological principles have evolved that now make it possible to make efficient and accurate estimates of the number of cells in well-defined biological structures. Central amongst these are the disector method of estimating particle number (Sterio, 1984) and systematic sampling strategies (Gundersen and Jensen, 1987; Gundersen et al., 1999). The proper application of these principles results in unbiased estimates of total number of cells that by defintion approach the true number without limit, as the sample size increases. They have the additional virtue of being highly efficient; typically only 100 to 200 cells need to be counted to obtain an estimate in an individual sample with a precision that is sufficient for most comparative and experimental histological studies (Gundersen, 1986).

There are two conditions that must be met for the proper application of these principles: the boundaries of the structure in which one is to make estimates must be well defined and the cells to be counted must be identifiable and distinguishable from other cell types (Gundersen, 1992). Meeting these conditions presents particular problems when estimating the number of neurons, glia, and endothelial cells in the cortex, because it is often difficult to distinguish between certain populations of glia and neurons. Today, the main obstacles for making unbiased estimates of the number of these cell types are no longer the availability of appropriate techniques for estimation of all numbers, but the development of standardized definitions of neocortex and of cell types within neocortex, that permit the new counting techniques to be applied properly.

In this paper, we have addressed these problems in the brains of rats. First, we have provided a definition of cortex based on reproducible anatomical landmarks, namely the rhinal fissure, in a series of frontal sections through the cortex. Secondly, we have provided a rigorous scheme for defining the various cell types in this region. The latter has had 
the consequence of markedly reducing the number of cells that fall into the uncertain category. Both the delineation of the area of interest and the cell classification scheme are compatible with the unbiased stereological methods used for estimation of the number of cells in rat brain cortex.

\section{HISTOLOGIC PROCESSING AND SAMPLING}

Three male albino Wistar rats (350 - $450 \mathrm{~g})$ were anesthetized and perfused via the aorta with a mixture of $1 \%$ glutaraldehyde and $3 \%$ formaldehyde in Tyrode solution at $120 \mathrm{~mm} \mathrm{Hg}$. The brains were removed and weighed. No significant differences between hemispheres were present; hence, one randomly selected hemisphere from each brain was placed in a $4 \%$ aqueous solution of formaldehyde. After immersion in a $6 \%$ agar solution maintained at $60^{\circ} \mathrm{C}$, each hemisphere was surrounded by the warm fluid of agar in a rectangular box and cooled to $5^{\circ} \mathrm{C}$. The hemisphere was then cut in frontal slabs of 1.5 $\mathrm{mm}$ thickness with a macrotome (device shown in Fig. 24 of Gundersen and Jensen, 1987) at room temperature. This procedure ensured that the ventricles and sulci are filled with agar and that the sections were parallel and equidistant (Braendgaard et al., 1990). The resulting slices were dehydrated in graded ethanol $(2 \times 70 \%$ and $2 \times 96 \%$ and $1 \times 99 \%)$ for one hour per step. The dehydrated tissue was infiltrated with glycol methacrylate (Historesin ${ }^{\circledR}$ ) without hardening catalyst, for $3 \times 24 \mathrm{hrs}$ at $4^{\circ} \mathrm{C}$, and then embedded in the

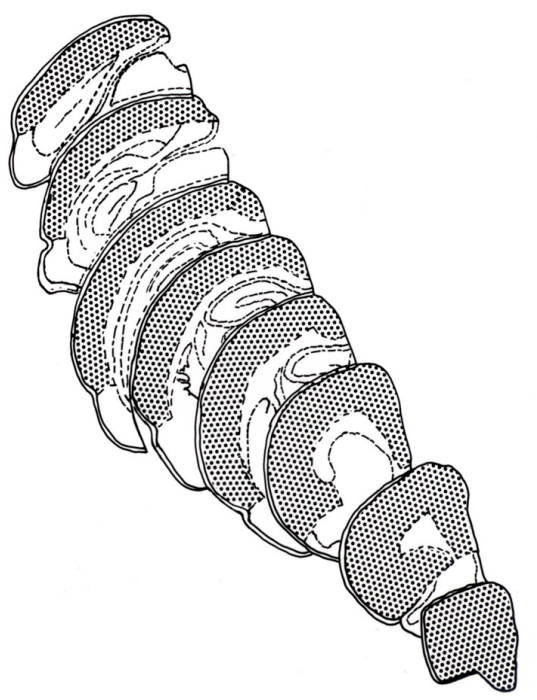

same medium (with the hardening catalyst). An LKB Historange ${ }^{\circledR}$ microtome was used to obtain one $20 \mu \mathrm{m}$ section from each plastic block. The sections were stained with Giemsa stain (West and Gundersen, 1990).

\section{DEFINING THE SYNCORTEX FOR STEREOLOGICAL STUDIES}

One problem faced by stereologists interested in cortical regions is that in most species there are few macroscopical landmarks that can be used to precisely identify cortex or its subdivisions, such as the neocortex. In addition, heterogeneous shrinkage, the effects of experimental treatment and human bias may result in variations in the positioning of the boundaries of the regions to be considered. By using basic landmarks that are readily apparent on histological slides of the rat brain such as the rhinal fissure, it is possible to consistently define a region that comprises neocortex, most of allocortex and parts of claustrum (Zilles and Wree, 1985; Paxinos and Watson, 1986) and can be used for many experimental studies (Fig. 1). We propose the term syncortex (from Greek syn meaning with, together) for that region.

The ability to analyze smaller regions of particularly neocortex will be largely dependent upon the developement of new histological and imaging techniques that would show accurately the borders of these regions.

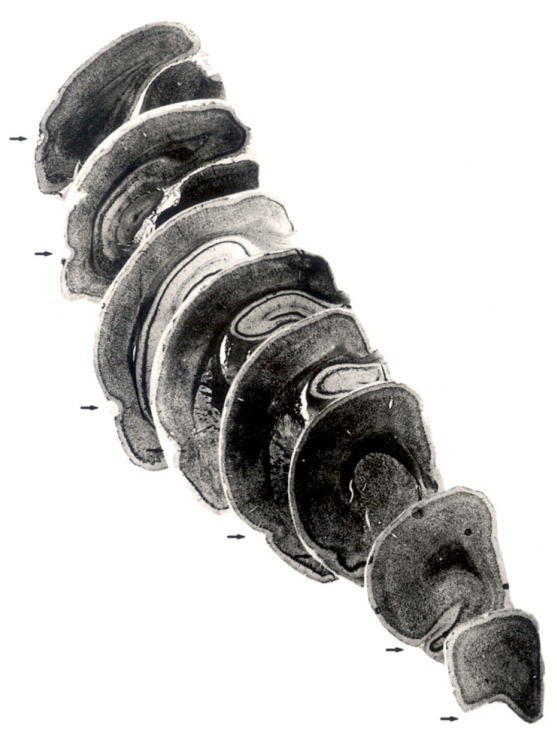

Fig. 1. Series of frontal sections through the right cerebral hemisphere of rat showing the borders of the syncortex. Diagrammatic representation of the syncortex to the left (shaded areas). Arrows point to the rhinal fissure, the lateral border of syncortex at most levels. Rostral, bottom right. 


\section{Estimation of the volume of the syncortex using Cavalieri's estimator}

The area of the region defined as syncortex on each slice is estimated by point-counting: the area associated with each point in the grid, a(p), in this investigation $1 \mathrm{~mm}^{2}$, is multiplied by $\mathrm{P}_{\mathrm{i}}$, the number of points lying over syncortex on the $i^{\prime}$ th frontal slice, to obtain an unbiased estimate of the area. The volume of the syncortex, $\mathrm{V}(\mathrm{Syn})$, is estimated according to Cavalieri's estimator using the formula (Gundersen and Jensen, 1987):

$$
V(\operatorname{Syn})=\bar{t} * a(p) * \sum_{i=1}^{n} P_{i}
$$

where $\bar{t}$ is the average frontal slice thickness, in this study $\bar{t}=1.5 \mathrm{~mm}$ before embedding, and $\mathrm{n}$ is the number of equidistant frontal slices through the region.

The coefficient of error $(\mathrm{CE}=\mathrm{SEM} /$ mean $)$ for these values have been estimated according to the procedure described in detail elsewhere (West and Gunderson, 1990; Gundersen et al., 1999). On average, the $\Sigma \mathrm{P}_{\mathrm{i}}$ obtained in the present study was 126 , with an average CE of 0.03 (See below: Estimation of the coefficient of error).

\section{Tissue shrinkage}

In order to justify the assumption that the reference volume is the same before and after processing of the tissue (i.e., dehydration, embedding, sectioning, staining, clearing and mounting), the tissue shrinkage was estimated according to the following formula:

shrinkage $=($ volume before processing - volume after processing)/(volume before processing),

(Braendgaard et al., 1990). Both volumes were estimated on the basis of the Cavalieri method. For the three hemispheres studied, the average shrinkage was 0.003 with a SEM of 0.073. Although this is not a negligible phenomenon, the actual shrinkage in this study is, for all practical purposes, without relevance when estimating the total number of cells.

\section{CRITERIA FOR CLASSIFICATION OF CORTICAL CELLS IN NISSL-STAINED, THICK PLASTIC SECTIONS USING OPTICAL DISECTORS}

\section{Introduction}

Distinguishing between neurons and glial cells in cortical regions has been a major problem for stereologists interested in estimating the number of these cells in Nissl-stained, thick plastic sections. One of the most important goals of the present study has been to describe a procedure by which cells in the syncortex can be classified in a way that makes it possible to distinguish between various types of cells and to quantify the degree of uncertainty in the classifications. A summary of the classification system established by the present study and the frequency of subtypes of each cell type appears in Table 1 .

Table 1. Classification of the cells in the rat syncortex using optical disector in Nissl-stained, thick plastic sections.

Major cell type (frequency of subtypes)

1. Neurons

1A. Well-defined (100\%)

a. With the sharpest image of the nucleus

i. Typical cortical neurons $(85 \%)$

ii. Neurons belonging to the "borderline" cortical cells (13\%)

b. Without a sharp image of the nucleus $(2 \%)$

2. Glial cells

2A. Well-defined (75\%)

a. Certain in number $(71 \%)$

b. Uncertain in number: Lack of certainty due to being adjacent to each other or overlapping in a manner that makes the borders of the nuclei uncertain $(4 \%)$

2B. Uncertain $(25 \%)$

a. Lack of certainty due to being adjacent to, appearing to be part of or attached to the neuronal soma, or appearing as a probable proximal portion of a neuronal process $(24 \%)$

b. Lack of certainty due to the overlap or interference of neurons $(1 \%)$

3. Endothelial cells

3A. Well-defined: Sharp image of the nucleus is recognized unambiguously (96\%)

3B. Uncertain: Lack of certainty due to morphology of nucleus (4\%) 


\section{Neurons}

Cortical neurons can be divided into 2 groups; pyramidal neurons and non-pyramidal neurons (Peters and Jones, 1984). Using the optical disector, a neuron is counted when a sharp image of its nucleus comes into focus within the disector sample (Gundersen, 1986; West and Gundersen, 1990). It is therefore the nuclei which are counted and not the somata and perikarya. The primary distinguishing features of the nucleus of a neuron at this level are that it is typically spherical or round and that the nucleoplasm is pale and homogeneous (Feldman, 1984). Although typical neuronal cell bodies and, in some cases, proximal portions of dendrites can be seen in the Nissl-stained (Vaughan, 1984) plastic sections, this limited amount of morphology is not adequate for a complete differential identification of all neuron types. Hence, for quantitative investigations, we propose the designation Group 1A (Table 1) for all types of "well-defined neurons", which actually, in this study, refers to all neurons (See below).

The surface of the neuronal nucleoplasm is typically smooth, though deep infoldings and/or intranuclear rods are occasionally seen in some neurons. Relatively slight condensations of chromatin are often observed either under the nuclear envelope or scattered in the nucleoplasm. If the nucleolus can also be seen, it is dark and condensed (Feldman, 1984) (Group 1Aai, Table 1) (Fig. 2a).
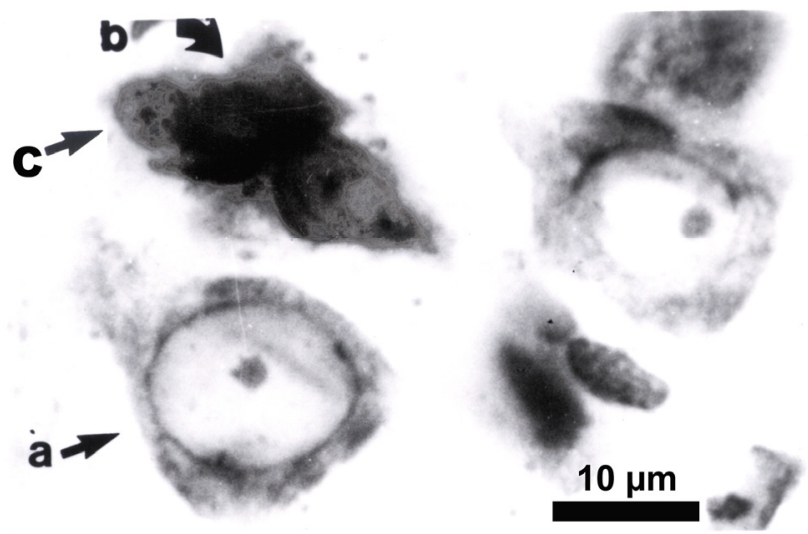

Fig. 2. A typical, well-defined neuron, at a sharp image in the focal plane (a). (b) Probable glial cell(s): the regions between the overlapping and/or the closely adjacent neurons are so dark that it is almost impossible to decide whether it contains a glial cell (See also Fig. 10c, curved arrow). (c) well-defined cortical glial cell (so close to the neuron that it is partly obscured).
The cytoplasm of some of the neurons stains so intensely that it is either difficult or sometimes almost impossible to recognize the nuclei (Group 1Ab, Table 1). In these cases, these neurons are counted when the first clear image of the cytoplasm (and according to the problem mentioned above not the nucleus) appears within the disector (Fig. 3a).

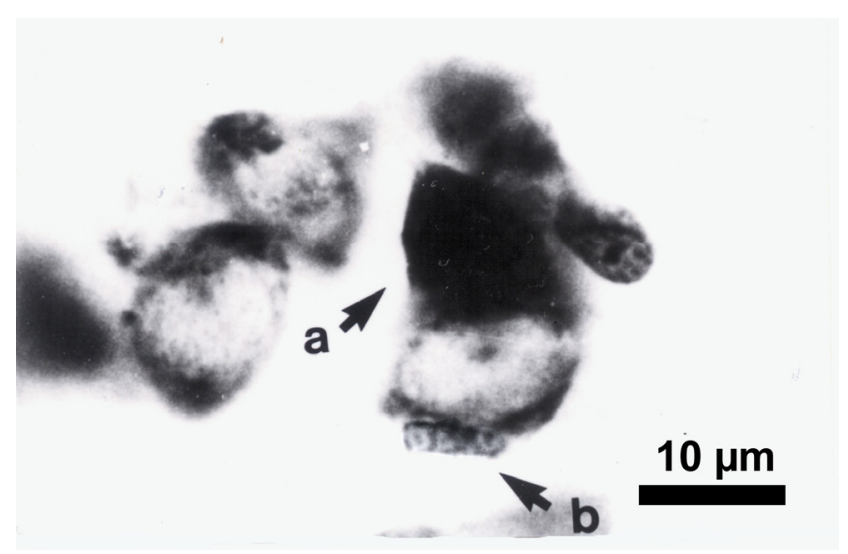

Fig. 3. A dark, well-defined neuron without a sharp image of the nucleus (a). The cytoplasmic feature and the visible proximal portions of the processes (i.e., axon and/or dendrites) permit the unambiguous identification of the cell as a neuron. Note also (the row of 3?) glial cell(s) (b) (See Fig. 8 for details concerning these types of glial cells).

\section{"Borderline" cortical cells}

Members of a relatively large group of cells with various combinations of features (so-called "borderline" cells) have been difficult to identify with certainty as either neurons or glial cells.

The size of a cell cannot be used to distinguish between cortical neurons and glial cells, knowing that nonpyramidal neurons also appeared in a variety of sizes (Peters and Jones, 1984). However, cortical borderline cells, which are either neurons or glial cells, have well-defined nuclei which are typically circular in form. Among these cells, those that have a sharp image of the nucleus with nucleoplasma, similar to that found in well- defined neurons (Fig. 4), are judged to be neurons (Group 1Aaii, Table 1). It is noteworthy that features of the nucleus of neurons belonging to "borderline" cortical cells and hippocampal granular cells have a very close resemblance. Therefore, in cases of doubt, cells were directly compared to hippocampal granular cells in order to facilitate the distinction. 


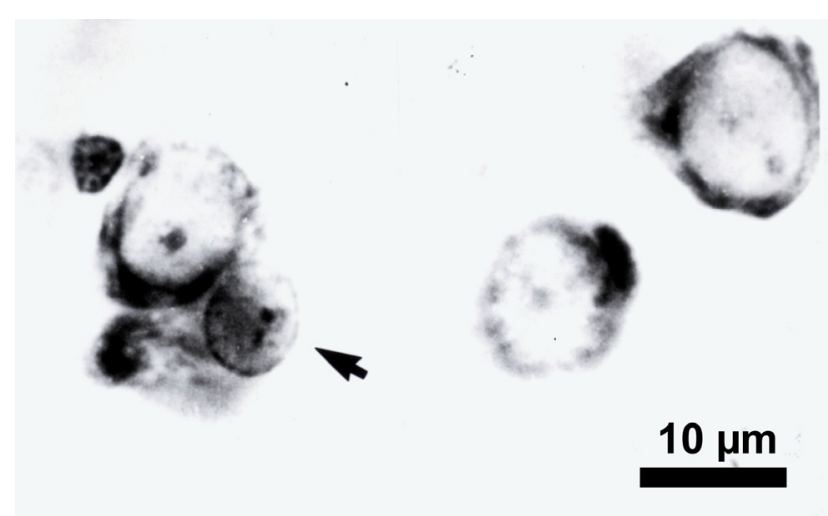

Fig. 4. A "borderline" cortical cell (arrow) which has a sharp image of the nucleus with a nucleoplasma similar to that found in well-defined neurons. These cells are very similar to hippocampal granular neurons. Note: the nucleolema appears as a visible ring, there is a lack of tiny chromatin particles and the nucleus has a prominent oval shape.

\section{Glial cells}

Glial cells are usually smaller than neurons and, in Nissl- stained preparations, only their nuclei stain well (Vaughan, 1984). Glial cells show a variety of features in their nuclei (Vaughan, 1984), and we have used the shape and features of the nucleus to distinguishing between glial cells and neurons. We therefore divided glial cells into two subdivisions, namely Group 2A, which consists of well-defined glial cells and Group 2B which are uncertain cells (Table 1).

\section{Group 2 A glial cells}

This group consists of well-defined cells that can be easily recognized as glial cells (Figs. 2c, 5a,b and 10). Group 2Aa (Table 1) refers to all those welldefined glial cells which can be counted unambiguously. Among the cells of this group, there are also cells belonging to two groups of borderline cells (Figs. 6 and 7a).

Group $2 \mathrm{Ab}$ represents the well-defined glial cells that are uncertain in number (Table 1) (Figs. 3b, 8a,b).

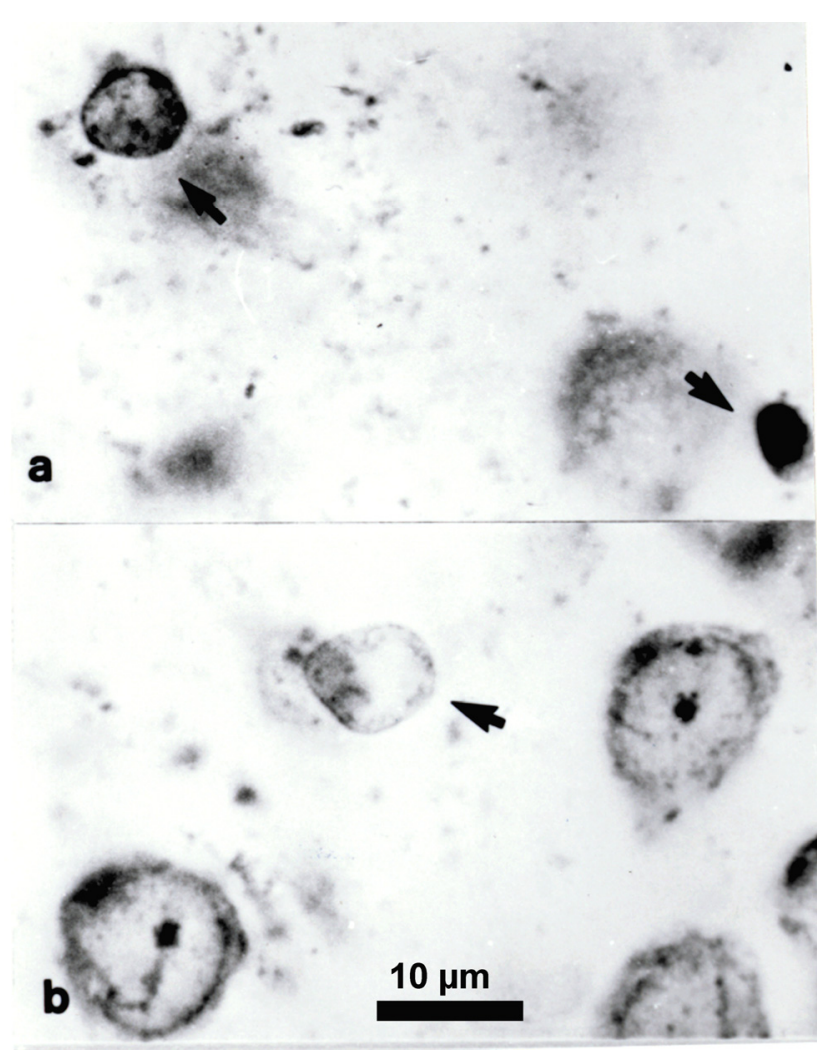

Fig. 5. Some examples of well-defined cortical glial cells (arrows in $a$ and $b$ )

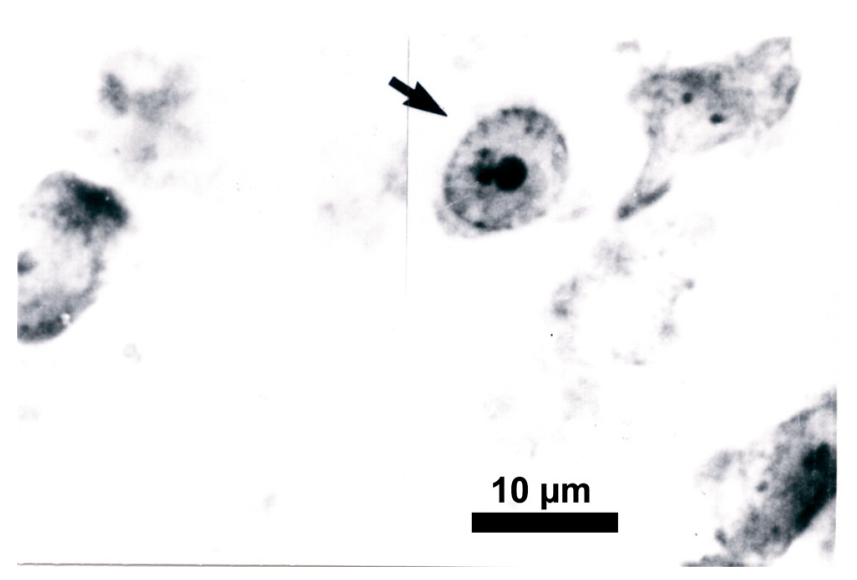

Fig. 6. A "borderline" cortical cell defined as a glial cell. Note the pale round nucleus with nucleolus and the darkened rim outlining the nuclear envelope (arrow). 


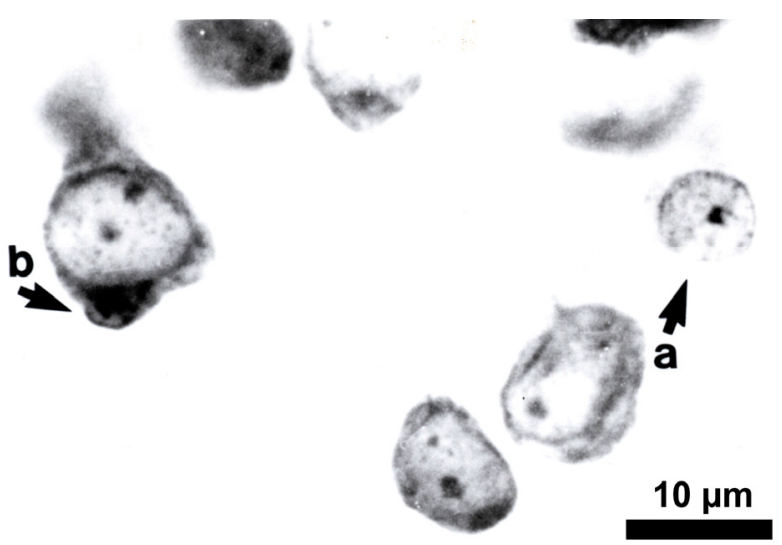

Fig. 7. "Borderline" cortical cell defined as glial cell (a). Note: the pale nucleoplasm has dispersed chromatin and lacks a visible nucleolema, the nucleus has a mat appearance, the nucleolema appears slightly wavy, and the small shape of the nucleus is more round than oval. The appearance of these cells differs from that of hippocampal granular neurons. An uncertain glial cell (b): either a small glial cell that appears to be adjacent to the neuron or a small round object with dark perimeter and a condensation-like particle in its center.

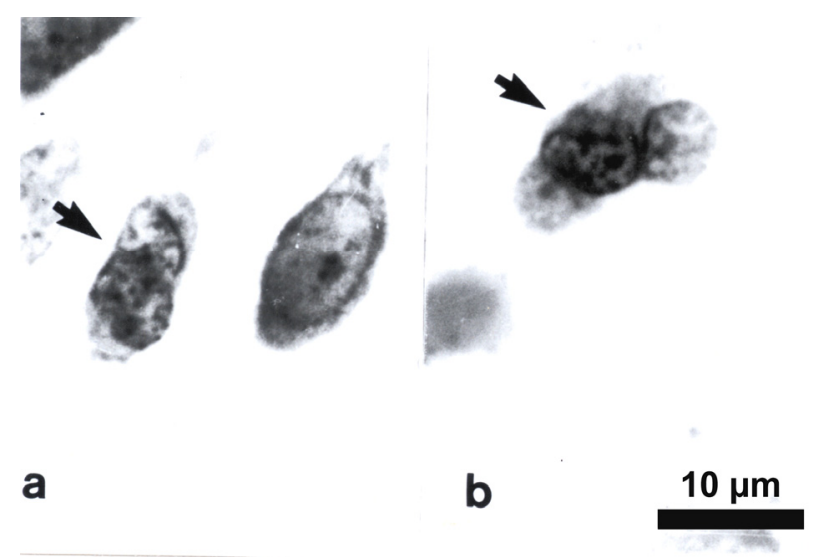

Fig. 8. Well-defined cortical glial cells which are adjacent to each other or overlapping (arrows). These features preclude the unambiguous determination of the border of the nuclei and, hence, the exact number of cells (see also Fig. 3b).

\section{Group 2B glial cells}

This group consists of uncertain glial cells. One type consists of either probable glial cells which appear to be adjacent to the neuronal soma or one of the following forms: (i) a conglomerate of dark particles (Figs. 9a,b) or (ii) a small round or oval object with a dark perimeter and a condensation-like particle in its center (Figs. $7 \mathrm{~b}$ and $9 \mathrm{~b}$ ). Either of these forms may appear in different ways, as described in Table 1 (Group 2Ba).
Sometimes, the region between two overlapping or closely adjacent neurons appears in a manner (e.g., darkly stained) that makes it almost impossible to decide with certainty whether or not it contains a glial cell, despite increasing the intensity of the light. This is especially so because some glial nuclei can be very flat, thin, small in size and sometimes very dark (Figs. 10a-c). In such cases we classify the cells as Group 2Bb (Table 1) (Fig. 2b).

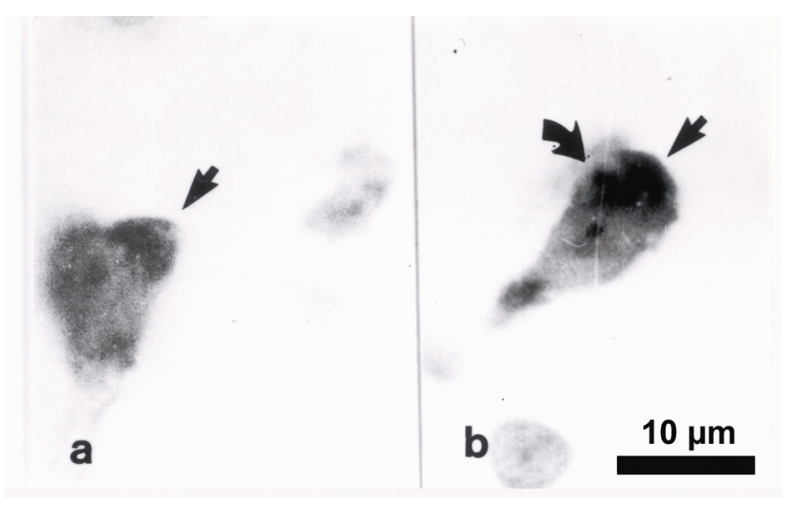

Fig. 9. Uncertain glial cells: Arrows indicate probable glial cell(s) which appear to be either adjacent to the neuronal soma or one of the following two possibilities: (i) a conglomerate of dark particles (straight arrows in $a$ and b) or (ii) a small oval object with dark perimeter and a condensation-like particle in its center (curved arrow in b).

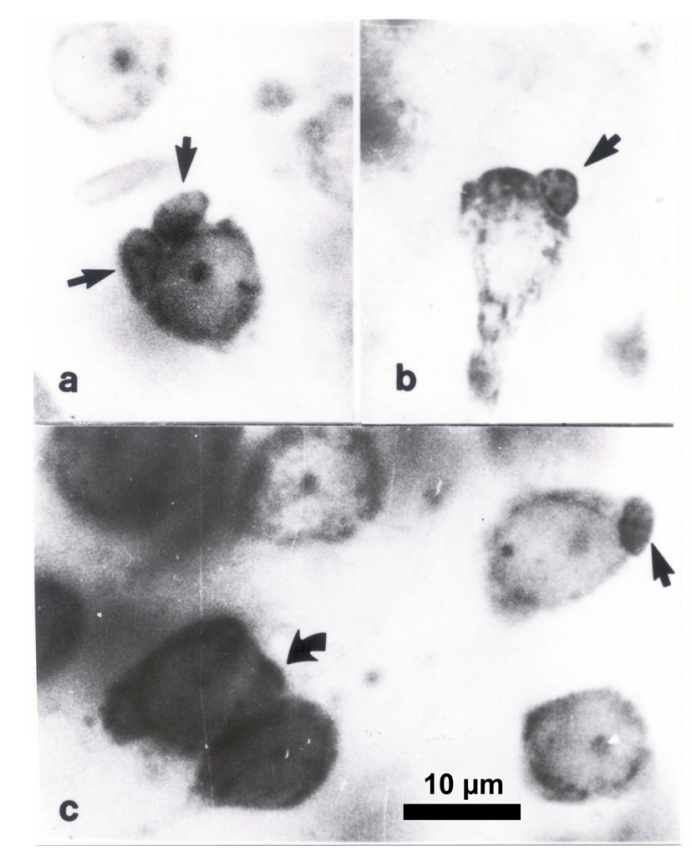

Fig. 10. Well-defined glial cells: Note that their nuclei can be very flat, thin, dark and small in size (straight arrows in $a, b$ and $c$ ). A probable glial cell, possibly located between two adjacent darkly stained neurons (curved arrow in c). 


\section{Endothelial cells}

Endothelial cells are counted when the sharpest optical image of the nucleus comes into focus in the disector. The nucleus in a well-defined endothelial cell is very dark and elongated and, in transverse sections of vessels, it appears sickle-shaped (Fig. 11a) while in longitudinal sections (Fig. 11b) (Group 3A, Table 1) it appears willow leaf shaped. Uncertain endothelial cells are described in Table 1 (Group 3B) (Figs. 12a,b).

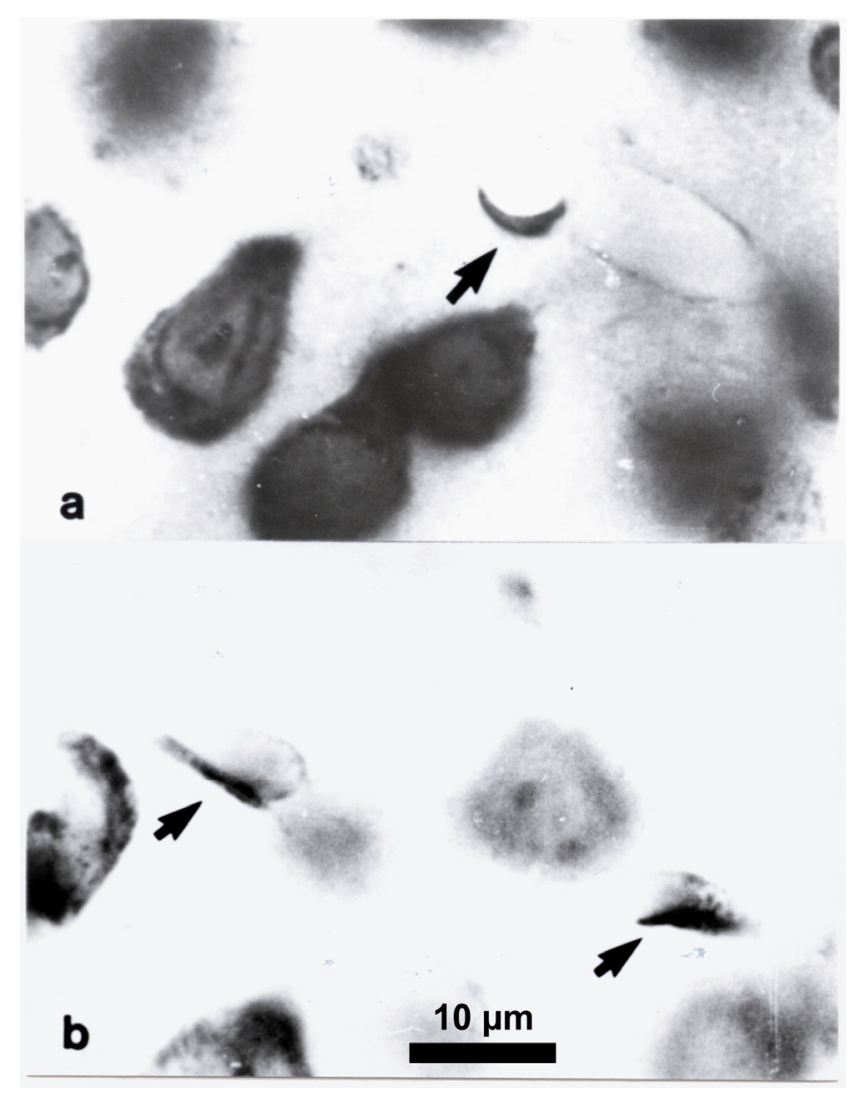

Fig. 11. A sickle-shaped, dark elongated well-defined nucleus of an endothelial cell in a transverse section of a cortical vessel (arrow in a). Arrows in $b$ indicate willow leaf-shaped dark, elongated well-defined nuclei of two endothelial cells in longitudinal sections of cortical vessels.

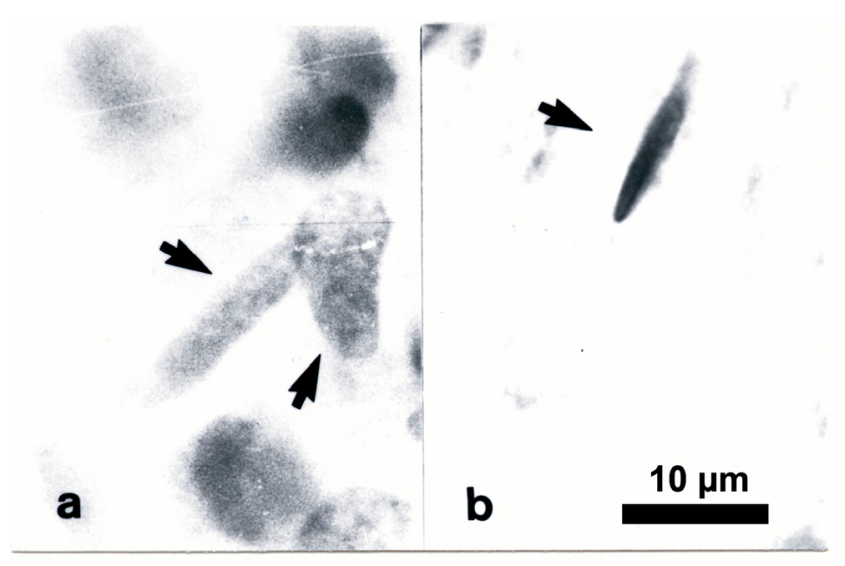

Fig. 12. Uncertain endothelial nuclei: unfolded endothelial nuclei or flat glial nuclei (arrows in a). Arrow in $b$ indicates an uncertain endothelial nucleus (an endothelial nucleus or a glial nucleus which is cut along its longitudinal axis. In the latter case the investigator may be focusing on the profile of a glial nucleus as it appears in a tangential section).

\section{UNBIASED ESTIMATION OF NUMERICAL DENSITY $\left(\mathrm{N}_{\mathrm{V}}\right)$ AND OF TOTAL CELL NUMBER (N)}

\section{ESTIMATING THE NUMERICAL DENSITY}

Unbiased estimation of numerical density $\left(\mathrm{N}_{\mathrm{V}}\right)$ of neurons (West and Gundersen, 1990) glial cells and endothelial cells in the rat syncortex were made by sampling the cortex in a systematic random manner with optical disectors (Gundersen, 1986).

The optical disector is an extension of the disector principle (Gundersen, 1986, Fig. 2.3; Gundersen et al., 1988; Braendgaard et al., 1990). In practise, one focuses down through a known thickness $h$ of the section in one continuous movement (West and Gundersen, 1990) and counts how many new cortical cell nuclei come into focus within a counting frame of known area. Each optical disector is a sample of cell density, Nv. 


$$
N v=Q^{-} /(h \cdot \text { frame area })
$$

Where $\mathrm{Q}^{-}$is the number of nuclei (of a particular cell type) that were counted in a disector and $h$ is height of the disector.

The mean of the density measures obtained from the multiple samples,

$$
\text { mean } N v=\Sigma Q^{-/ h} \Sigma(\text { frame area })
$$

Where $\Sigma Q^{-}$is the total number of nuclei (of a particular cell type) that are counted in all of the disectors. This is an unbiased estimate of the Nv or numerical density.

\section{ESTIMATING TOTAL CELL NUMBER}

The estimate of $\mathrm{N}$, total number of cells of a particular type is:

$$
N=\text { mean } N_{V} V_{R E F}
$$

Where $\mathrm{V}_{\mathrm{REF}}$ is the volume of syncortex estimated with the Cavalieri point counting in the syncortex of one hemisphere multipled by 2 to give an estimate of the total number of cells in both hemispheres.

In our investigation of 3 rat brains, an average of 10 evenly spaced plastic sections were prepared from one randomly selected hemisphere of each animal (see: Histologic processing and sampling). All of these ca. 10 sections were used to estimate the $V_{\text {REF }}$ (see above). For estimating the $\mathrm{N}_{\mathrm{V}}$ values, five slides were chosen for each hemisphere in a systematic random manner through the entire extent of the hemisphere. Syncortical areas were delineated on the undersides of the slides to be examined, with an ultrafine, felttipped, waterproof marking pen, using a dissection microscope. The specimen stage was motorized in the $\mathrm{x}, \mathrm{y}$-directions for facilitating the stepwise, predetermined movements in these directions when the sampling positions on the sections were chosen in a systematic random manner.

For measuring the movement of the specimen stage, a Heidenhain ${ }^{\mathcal{O}}$ VRZ 401 electronic microcater, with a precision of better than $0.5 \mu \mathrm{m}$ in the $\mathrm{z}$ axis, was used (Gundersen et al., 1988; Braendgaard et al., 1990). In this study, frame size in $\mathrm{mm}$ was 350 (horizontal) and 265 (vertical). Using an average magnification of 3826, fifteen fields of view were sampled in each slide, on average. Four frames, with an average area of $529.6 \mu \mathrm{m}^{2}$ for each frame, were used to count the syncortical cells in each field of view. The height of the disector was $10 \mu \mathrm{m}$ in this investigation. Neurons, with the exception of neurons belonging to the "borderline" cortical cells, were sampled in 2 diagonal frames (upper left and lower right). The "borderline" cortical cells were sampled in all 4 frames, whereas glial cells were sampled in one frame (upper left), and endothelial cells were sampled in 3 frames (the two upper frames and the right lower frame).

Stereological parameters of this investigation appear in Table 2.

\section{ESTIMATION OF THE COEFFICIENT OF ERROR}

The following formula was used in this investigation for estimating the average coefficient of error for three brains (Table 2):

$$
\overline{C E}=\sqrt{\left[\left(C E_{1}^{2}+C E_{2}^{2}+C E_{3}^{2}\right) / 3\right]},
$$

where

$$
C E=\sqrt{\text { TotalVar }} / \sum Q^{-} .
$$

Table 2. Stereological parameters in rat syncortex (both hemispheres) using optical disector in Nissl-stained, $20 \mu \mathrm{m}$ plastic sections.

\begin{tabular}{llllll}
\hline Rat & $\begin{array}{l}\mathrm{V}(\text { syn }) \\
\mathrm{mm}^{3}\end{array}$ & $\begin{array}{l}\mathrm{N}_{\mathrm{v}} \text { (neurons) } \\
10^{3} / \mathrm{mm}^{3}\end{array}$ & $\begin{array}{l}\mathrm{N}(\text { neurons }) \\
\times 10^{6}\end{array}$ & $\begin{array}{l}\mathrm{N} \text { (glia) } \\
\times 10^{6}\end{array}$ & $\begin{array}{l}\text { N(endothelial) } \\
\times 10^{6}\end{array}$ \\
\hline 1 & 357 & 178.43 & 63.70 & 38.10 & 24.37 \\
2 & 390 & 154.00 & 60.06 & 54.92 & 28.42 \\
3 & 390 & 150.26 & 58.60 & 40.00 & 16.60 \\
\hline Mean & 379 & 160.90 & 60.79 & 44.34 & 23.13 \\
CV & 0.053 & 0.096 & 0.041 & 0.208 & 0.261 \\
CE & 0.03 & & 0.10 & 0.15 & 0.12 \\
\hline
\end{tabular}


The total variance was calculated according to the following formula:

$$
\text { Total var }=\sum Q^{-}+\operatorname{Var}_{\text {SURS }},
$$

where SURS stands for systematic uniform random sampling (See Gundersen et al., 1999).

$\operatorname{Var}_{\text {SURS }}$ is calculated as follows (See Gundersen et al., 1999):

$$
\operatorname{Var}_{\text {SURS }}=\left(3\left(A-\sum Q^{-}\right)-4 B+C\right) / 240
$$

where

$$
\begin{aligned}
& A=\sum_{i=1}^{n}\left(Q_{i}^{-} \times Q_{i}^{-}\right), B=\sum_{i=1}^{n}\left(Q_{i}^{-} \times Q_{i+1}^{-}\right), \\
& \text {and } C=\sum_{i=1}^{n}\left(Q_{i}^{-} \times Q_{i+2}^{-}\right),
\end{aligned}
$$

$\mathrm{Q}_{\mathrm{i}}^{-}$is the total number of cells counted in a total disector volume in the syncortex of the $i^{\prime}$ th section, and $\mathrm{n}$ is the number of sections.

\section{DISCUSSION}

The disector has been used in a number of studies to obtain unbiased estimates of the number of neurons in rat cortex (see, for example, Korbo et al., 1990). However, methodological problems related primarily to non-stereological aspects of the methodology, such as defining the anatomical area and identifying cell types unequivocally, have received relatively little attention. The present report describes a procedure for obtaining an unbiased estimate of the numbers of cells (i.e., neurons, glial cells and endothelial cells) in the cortex of rat brain which takes these general problems more fully into account.

Mammalian cortex is notorious for variations in cell density between cortical areas. In particular, a large density variation is present between layers. Cell density is one of the key factors that defines the layers. Under these circumstances only one sampling strategy can provide correct, unbiased estimates: uniform random sampling at all sampling levels (sections, field of vision, and disectors). The present study describes such a design. The uniform random sampling design ensures that all areas and all layers and all cells are given an equal probability of being sampled and provides the correct average densities (Table 2) with the inhomogenities represented as a part of the relative variance of the estimators (CEs).
With regard to defining the anatomical area to be studied, there are few anatomical macroscopical landmarks that can be used to precisely identify cortex or its subdivisions such as the neocortex. Furthermore, experimental conditions may produce changes so that the borders of the anatomical regions differ from brain to brain. Korbo et al. (1990) used a stereotaxic atlas for defining the border of the rat cortex and included both the neo- and rhino-cortex. Tandrup and Braendgaard (1992) also used an atlas for the boundaries of the neocortex and stated that "the neocortex was frontally defined as the cortex rostral to the rhinal fissure and the entorhinal cortex occipitally". That definition was also used in a subsequent study (Licht et al., 1994). In our hands, however, these methods were found to be inadequate, partly because the term "neocortex" has a clear-cut definition in neuroanatomical terminology (Zilles and Wree, 1985) which differs from the use of the term in those stereological studies, and partly because of problems such as heterogeneous shrinkage and uncontrolled effects of experimental treatments and human bias, as pointed out above.

According to the present method, the total number of neurons in rat brain syncortex is 60.8 million on average, which departs markedly from previous estimations. In a study by Korbo et al. (1990), cells were identified as nerve cells when the nucleus was surrounded by Nissl-stained cytoplasm. According to their definitions, the total number of neurons in rat brain cortex was estimated to be an average of 20 million. Similarly, Tandrup and Braendgaard (1992) defined neuronal nuclei as nuclei surrounded by a clearly visible cytoplasm. Additionally, they stated that "other factors such as a light nucleus with a few granules, the quality of the nucleolus, and the staining intensity were also taken into account". Using their procedures, an average of 24.5 million neurons was estimated in the region called neocortex. Licht et al. (1994) obtained an average of 30.8 million neurons in a subsequent study using the methods and definitions of Tandrup and Braendgaard (1992), while none of the above mentioned studies have estimated the number of glial or endothelial cells. The discrepancies between studies might stem from differences between the cell classification and cell counting procedures. Previous studies have attempted to define neurons, but their definitions may have been insufficient to include all types of neurons. In addition, they may have been unable to sort neurons and non-neurons sufficiently. The present method requires that distinctions be made by the 
investigator in order to classify each and every cell. The present meticulous procedure may have resulted in counting neurons in the rat brain that may have escaped the attention of previous studies. It is noteworthy that a study on human brain showed a relative abundance of small neurons with a pericaryon volume of less than $1000 \mu^{3}$, roughly a neuron diameter of $12 \mu \mathrm{m}$ or less (Gundersen et al., 1988).

The present methods were developed in order to make a classification of all syncortical cells in such a way that each cell could be placed as unequivocally as possible in a particular category. One of the major advantages of the present method is that it takes uncertainties in the counting procedure into account and, furthermore, it quantifies those uncertainties on the basis of our syncortical cell classification system. Moreover, the total number of syncortical cells may be estimated with a reliable degree of certainty. The categories can be used in quantitative estimates of syncortical cells based on the application of the optical disector to Nissl-stained thick plastic sections.

Conventionally, a cell is counted when the first sharp image of its nucleus comes into focus in an optical disector (Gundersen et al., 1988). However, limitations in the use of Nissl-stained thick plastic sections preclude making distinctions between the various types of glial cells. Therefore, we have used the general term glial cells for this group of cells.

Cortical cells with various combinations of features (i.e., "borderline" cells) have perhaps presented the biggest problem for making clear-cut distinctions between some neurons and various types of glial cells. Such cortical cells have nucleoplasmic chromatin which is less dispersed than that of glial cells which resemble them, and a well-defined nucleus with a condensed nucleolus, similar to typical neurons. Neurons belonging to borderline cells make up between 8 and $16 \%$ of the total number of neurons. The remaining borderline cells were classified as belonging to glial cells.

Unbiased estimates of the number of cells in the syncortex is compromised by the various patterns of both locations and uncertain forms of cells in the tissue. This problem is a very common source of bias in the estimates of glial cells, while it is less problematic in the estimates of the number of neurons and endothelial cells in the syncortex. It is noteworthy that $25-35 \%$ of glial cells were classifed as uncertain. Hence, the relatively high percentage of glial cells that were positioned in such a manner that uncertainties arose in the counting procedure indicates that the estimate of the number of glial cells may not be unbiased. Thus, further work on the unambiguous identification of glial cells is required in order to obtain an unbiased estimate of the number of glial cell in the syncortex.

In conclusion, the present study indicates that the mean total number of cells (neurons, glial and endothelial) in the syncortex of the rat brain is $128 \times 10^{6}$. The total number comprises $114 \times 10^{6}$ cells that were classified as being in a certain category and $14 \times 10^{6}$ cells that were in an uncertain category. We believe that the present procedure provides a reliable and valid basis for further stereological investigations of the syncortex in the rat brain.

\section{ACKNOWLEDGEMENT}

We thank Hans Jørgen G. Gundersen, Mark West, Jens Zimmer and Steven Mark Evans for their encouragement and constructive comments during the preparation of this manuscript, Anette Funder, Maj Britt Lundorf, Lone Meldgård, Tina Nygaard, Anette Larsen, Bodil Kjær and Kim Kjelberg for their skilful help, and the Danish Medical Research Council for financial support.

\section{REFERENCE}

Braendgaard H, Evans SM, Howard CV, Gundersen HJG (1990). The total number of neurons in the human neocortex unbiasedly estimated using optical disectors. J Microsc 157:285-304.

Feldman ML (1984). Morphology of the neocortical pyramidal neuron. In: Peters A, Jones EG, eds. Cerebral Cortex. Vol. 1. Cellular Components of the Cerebral Cortex. New York: Plenum Press, 123-200.

Gundersen HJG (1986). Stereology of arbitrary particles. A review of unbiased number and size estimators and the presentation of some new ones, in memory of William R. Thompson. J Microsc 143:3-45.

Gundersen HJG (1992). Stereology: the fast lane between neuroanatomy and brain function - or still only a tightrope? Acta Neurol Scand 137(suppl):8-13.

Gundersen HJG, Bagger P, Bendtsen TF, Evans SM, Korbo $\mathrm{L}$, Marcussen $\mathrm{N}$ et al. (1988). The new stereological tools: Disector, fractionator, nucleator and point sampled intercepts and their use in pathological research and diagnosis. APMIS 96:857-81.

Gundersen HJG, Jensen EB (1987). The efficiency of systematic sampling in stereology and its prediction. J Microsc 147(3):229-63.

Gundersen HJG, Jensen EBV, Kiêu K, Nielsen J (1999). The efficacy of systemic sampling in stereology reconsidered. J Microsc 193(3):199-211. 
Korbo L, Pakkenberg B, Ladefoged O, Gundersen HJG, Arlien-Søborg P, Pakkenberg H (1990). An efficient method for estimating the total number of neurons in rat brain cortex. J Neurosc Methods 31:93-100.

Licht RW, Larsen JO, Smith D, Braendgaard H (1994). Effect of chronic lithium treatment with or without haloperidol on number and sizes of neurons in rat neocortex. Psychopharmacology 115:371-4.

Paxinos G, Watson C (1986). The Rat Brain in Stereotaxic Coordinates. Orlando Fl: Academic Press.

Peters A, Jones EG (1984). Classification of cortical neurons. In: Peters A, Jones EG, eds. Cerebral Cortex. Vol. 1. Cellular Components of the Cerebral cortex. New York: Plenum Press, 107-21.

Sterio DC (1984). The unbiased estimation of number and sizes of arbitrary particles using the disector. $\mathrm{J}$ Microsc 134:127-36.

Tandrup T, Braendgaard H (1992). The number and mean volume of neurons in the cerebral cortex of rats intoxicated with acrylamide. Neuropathol Appl Neurobiol 18:250-8.

Vaughan DW (1984). The structure of neuroglial cells. In: Peters A, Jones EG, eds. Cerebral Cortex. Vol. 2. Functional Properties of Cortical Cells. New York: Plenum Press, 285-329.

West MJ, Gundersen HJG (1990). Unbiased stereological estimation of the number of neurons in the human hippocampus. J Comp Neurol 296:1-22.

Zilles K, Wree A (1985). Areal and laminar structure. In: Paxinos G, ed. The Rat Nervous System. Orlando Fl: Academic Press. 